\title{
(Re)Descobrimento do Brasil
}

Quem foi que inventou o Brasil?

Foi seu Cabral, foi seu Cabral

No dia 22 de abril

Dois meses

Depois do Carnaval

(Lamartine Babo)

COMOTODOSAPRENDEM Osnasescolasbrasileiras, os navegadores portugueses chegaram ao Brasil em 1500. Desde então, esseevento tem sido objeto de controvérsias (casualidade? intencionalidade dos navegadores?) e disputas(quemosteriaprecedido? espanhóis? franceses? africanos?). A cima das polêmicas, o que continua sendo ensinado é que a frota comandadapor PedroÁlvaresCabral realizou o primeiro contato oficial de Portugal com a nova terra a $16^{\circ}$ Sul e a identificou como possessão Del Rey, chegando mesmoanomeá la: Terra de Santa Cruz. Num certo sentido, é justamente essa cruz que, santa ou vera, tem permanecido no centro das representações do (assim chamado) D escobrimento. Que foi feito carta, mais tarde pintura e, como veremos, cinema.

É portanto disto que trata este trabalho: de algumas representações que se fazem desse atofundador doBrasil, ou melhor, do processo discursivo quelevou à invenção do Brasil tal como o conhecemos hoje. Muitas questões podem ser levantadas a respeito dessas representações. Algumasquemeinteressarão aqui: quais as estratégias estéticas e as posicionalidades políticas que informaram essas representações? E - em se tratando de representações maisantigas, como éo caso da célebreC arta deCaminha-queressonâncias nos deixam na atualidade?

\section{A Carta}

O primeiro documento oficial que registra o (que chamarei aqui de) Descobrimento, é a 
Carta a El-Rey dom M anuel, redigida pelo escrivão Pero Vaz de Caminha. O autor é generoso com a dadivosa natureza da região de Porto Seguro. Além disso, a minúcia de seu relato faz da Carta o primeiro relato etnográfico sobre os nativos, descrevendo modosdevida, fisionomiaseartes. O escrivão se esforça em convencer a corte portuguesa de que valia a pena investir na nova posse, e não surpreende que a Carta já tenha sido definida também como a primeira peça publicitária produzida nestas plagas. Caminha usa dos argumentos comuns na época - que incluem não apenas as possibilidades econômicas, como também a oportunidadedeseexpandir a cruzada cristã pelo mundo. Não devemos nos esquecer que a expulsão dos muçulmanos da península ibérica era fato recente, ea expansão católica era um componente importantíssimo da colonização. Fica clara, no discurso de Caminha, a justaposição da empresa colonial e da cruzada religiosa. Daí a freqüência com que se refere à possibilidade de conversão dos nativos, que não possuiriam religião e estariam prontos para receber a fé cristã:

“E segundo o que a mim e a todos pareceu, estagente, nãolhesfaleceoutra coisa para ser toda cristã, do que entenderem-nos (...) por ondepareceu a todos que nenhuma idolatria nem adoração têm. E bem crei o que, seVossa Alteza aqui mandar quem entre eles mais devagar ande, que todos serão tornados e convertidos ao desejo de Vossa Alteza." 1

N esse quadro, a construção eo assentamento dacruz são acontecimentos centrais do relato, assim como a descrição das primeiras missas realizadas. Escrevo missas no plural, poissão duas as cerimônias descritas pelo escrivão na Carta.

A "primeira" propriamente dita aconteceu no domingo da Pascoela, logo apósa chegada dos navegadores; a "segunda" foi realizada na sexta-feira, primeiro demaio. Ao quetudo indicaareação dosindígenasfoi bemdiferente em cada cerimônia. Deacordo com Caminha, na "primeira", logo após o sermão de frei Henrique, osíndiosseanimarame“tangeram cornoou buzinaecomeçaramasaltar edançar umpedaço", ${ }^{2}$ surpreendendo os portugueses.

Estamos longe, aqui, dos índios devotos e compenetrados que constam das representaçõestradicionaisdaPrimeiraM issatal como tem sido representada nos compêndios escolares. Entretanto, mesmo que o comportamento dos nativos tenha escandalizado algunsportugueses, Caminhanão oscensura, documentando seu gesto com a mesma compaixão com que se refere às suas vergonhas expostas pela nudez.

A segunda missa, pela descrição de Caminha, é provavelmente a que se toma por ser a Primeira. É que durante os dias em que permaneceram em Porto Seguro, os portugueses teriam dado freqüentes mostras de devoção religiosadiantedosnativos, beijando a cruz e distribuindo rosários. E portanto na segunda missa, sempre de acordo com Caminha, o respeito foi maior:

"Ali estiveram conosco, [assistindo] a ela, perto de cinqüenta ou sessenta [indígenas], assentados todos de joel ho assim como nós. E quando se veio ao Evangelho, quenoserguemostodosem pé, com as mãos levantadas, eles se levantaram conosco, eal çaram asmãos, estando assim até se chegar ao fim; e então tornaram-sea assentar, como nós. E quando levantaram a Deus, que nos pusemos de joelhos, eles se puseram assimcomo nósestávamos, comasmãos levantadas, eemtal maneirasossegados que certifico a Vossa Alteza que nos fez muita devoção." 3

E mesmo que nem todos os nativos tenham reagido da mesma forma, Caminhafocaliza o primeiro testemunho do efeito da fécristã na nova possessão, o que teria confirmado aos europeus a importância de sua cruzada: 
“E alguns deles, por o Sol ser grande, levantaram-se enquanto estávamos comungando, e outros estiveram e ficaram. Umdeles, homem decinqüenta ou cinqüenta ecinco anos, seconservou ali com aqueles que ficaram. Esse, enquanto assim estávamos, juntava aqueles que tinham ali ficado, e ainda chamava outros. Eandando assimentre eles, falando-Ihes, acenou com o dedo para o altar, e depois mostrou com o dedo para o céu, como se lhes dissesse alguma coisa de bem; e nós assim o tomamos!" 4

A descrição de Caminha confere uma aura mística a esse testemunho, montando uma cena solene, em tom dramático. O Homem de Cinqüenta Anos parece ter sido tomado por uma esperiência cósmica. No entanto, é preciso lembrar que entre uma missa e outra o contato entre portugueses e indígenas já havia se intensificado, sendo razoável supor umesforçoimediato decatequização por parte do clero a bordo.

\section{O Quadro}

Eu disse acima que a Carta foi o primeiro relato do Descobrimento, mas isso não deve ser tomado ao pé da letra. Houve outros relatos, como por exemplo o do Piloto A nônimo da esquadra deCabral, quecirculou entreos diversos cronistas daqueleevento. A própria Carta de Caminha dormiu por quase três séculos nos arquivos daTorredoTombo, até ser descoberta em 1773 pelo guarda-mor do arquivo, JosédeSeabradaSilva. Veio a ser publicada apenas em 1817, como parte da obra Corografia Brasílica, de Aires de Casal. Foi a partir da publicação que a Carta ficou estabelecida como principal documento comprovador do Descobrimento. E foi esse texto queinspirou o íconemais conhecido do evento: oquadroapropriadamenteintitulado A Primeira M issa, realizado 350 anos depois do Descobrimento, pelo catarinense Vitor Meirelles. Essa imagem - uma encomenda de Pedro II - viria a ser consagrada como a representação pictórica oficial do evento.

Na obra de Meirelles, uma luz intensa flui do plano de fundo e atinge a figura de frei Henrique, no momentoliminar da eucaristia. Os portugueses se mostram próximos desse centro, em posturadecontrição. Osindígenas circundam a cena em massa, ocupando inclusive o sombrio primeiro plano (onde se destaca a figura clara de uma mulher amamentando). Com exceção das poucas crianças, todos os indígenas se mostram absolutamentefascinadoscom a cerimônia, e não são poucos os queapontam para o centro iluminado da cena. O quenos remete, éclaro, à descrição detalhada que Caminha faz da "segunda" missa. Mas ao contrário de Caminha, que descreve como o sol intenso terialevadomuitosdosindígenasaabandonar o ilhéu escolhido pelos portugueses para o ritual, o quadro deM eirelles mostra um local cheio degrandes árvores esombra aprazível.

Emseu trabalho, Meirellesaplicouaelaborada técnica da pittura di fantasia, um estilo de pintura de paisagens em que elementos de locaisdiferentessão (re)combinados, compondo uma colagem. A paisagem é, dessemodo, o resultado da articulação de elementos colhidos em locais distintos. Parte d'A Primeira M issa, por exemplo, foi pintada durantea estada de Meirelles em Paris, onde viveu muitos anos, sempre patrocinado pelo imperador Pedro II. Outros detalhes, no entanto, foram produzidos nos arredores da IlhadeSanta Catarina (localizadaa 27-Sul), e desdequeA Primeira M issa de Meirelles veio a público, muitas comunidadesdaregião têm alimentado um debate em torno do quadro, comprovando que tal árvore está representada, ou que a luz de tal praia deu o tom. No entanto, mesmo quea pai sagem mostrada no quadro transcreva a temperatura subtropical do litoral catarinense, ela deve representar a florestatropical da região dePorto Seguro, no Sul da Bahia. ${ }^{5}$ Essa substituição de uma paisagem pela outra, em todo caso, vem a cal har coma própriaidéia da Primeira Missa, 
quepor sua vez éfruto deuma articulação de eventos, combinando a anterioridadedeuma cerimônia com os efeitos de outra.

\section{O Filme}

O trabal ho de Meirelles tornou-se um ícone onipresenteno culto dos valores nacionais. A cena consta de inúmeros livros didáticos, estampas, folhinhas, seloseatémesmo nalata debiscoitosPiraquê, popularíssimosnosanos 30 e40. A Primeira M issa deM eirelles também serviu de guia para a concepção cênica de D escobrimento do Brasil, filme que Humberto Mauro realizou em 1937. D escobrimento do Brasil foi financiado pelo Instituto do Cacau da Bahia: a instituição reunia latifundiários interessados em promover a importância histórica da Bahia. Também é significativo que este tabal ho tenha sido produzido pelo INCE - o Instituto Nacional do Cinema Educativo - , que havia sido criado como órgão do recém-fundado Ministério da Educação e Cultura. O MEC e outras iniciativasinstitucionaissurgiramsobaégide do programa de modernização do regime liderado por Getúlio Vargas.

D escobrimento do Brasil marca um momento importantenocinemabrasileiro: ofilmeindica o papel ativo doEstado na produção detextos que tinham por objetivo a educação ideológica do público (a partir daquele momento, a participação do Estado no cinema brasileiro - como censor ou produtor - seria constante e íntima, pelo menos até o final dos anos 80). A participação dos próprios cineastas no aparato estatal se tornaria comum; o próprio Mauro ocupou o cargo de diretor técnico do INCE. O fortenacionalismo que permeava o regime de Vargas serviu para a cooptação de intelectuais identificados com correntes políticas distintas, e que, às vezes relutantemente, se alinharam com o governo por princípios de patriotismo. Foi esse o quadro que Mauro encontrou no MEC. O cineasta abraçou a oportunidade e promoveu a realização de muitos filmes, especialmente documentários de caráter didático.

Apesar de se tratar de texto ficcional, dramatizado - não se caracterizando como documentário no sentido restrito-, D escobrimento do Brasil se apresenta como material di dático, destinado a uso educacional. E desse modo, longe de questionar os "eventos históricos", ofilmeassumeosregistrosoficiais prevalecentes em 1937. Por isso mesmo, o texto básico que serviu de argumento para o filme foi a Carta de Caminha.

No filme, Caminha é apresentado como personagem-narrador dos eventos; freqüentemente mostrado em primeiro plano, seu semblante é compenetrado, e seu ol har ante os indígenas é sempre pio e compassivo. Ele éfreqüentementemostradoescrevendo (como convém a um escrivão), e um fac-simile da carta ocupa atela, conferindo a autenticidade documental necessária ao filme. A s palavras do escrivão são transcritas em linguagem audiovisual em sua literalidade - em certas seqüências as próprias palavras são inscritas na tela para descrever o quejá sevê: écomo se as palavras citadas graficamente fossem necessárias para corroborar o caráter de verdade da cena já composta na tela.

Mauro escolheu um estilo de representação claramente realista. O resultado, ainda que não se equipareaos padrões hollywoodianos da época, sugere um grande esforço naquela direção. ${ }^{6}$ A produção põe em prática as convenções consagradas pelos filmes históricos. Apesar de não ter filmado na Bahia, masnolitoral fluminense(a22 Sul), o cenário queservedecaravelaportuguesa, osfigurinos e os objetos de cena correspondem a uma cuidadosa "reconstrução histórica", obviamente revelando a extensiva pesquisa bibliográfica e museológica da equipe de Mauro. A autenticidade é ainda reafirmada pela participação do especialista Roquette Pinto na coreografia dos personagens indígenas. E a música de Villa-Lobos desempenha um papel central na narrativa, fazendo referências às tradições musicais 
européias e ameríndias. $\mathrm{Na}$ época, o compositor colaborava ativamente com o Estado N ovo e escrevia peças de conteúdo nacionalista para grandes corais e orquestras sinfônicas.

O filme retrata a travessia do Atlântico com detal hes do cotidiano dos marinheiros e dos oficiais. Os marinheiros cantam saudosos e melancólicos. Cada nova etapa da viagem é pontuada pela imagem deum mapa, em que a frota de Cabral é representada por uma pequenaesferaquedeslizaem direção àcosta brasileira. A narrativaseguecuidadosamente al gumas das noções que ajudaram a consolidar aimagem do colonizador português triste e cordial, que veio interagir com indígenas e africanos, compondoassimo caráter nacional . Além de coincidir com o apogeu do nacionalismo getulista, D escobrimento do Brasil vem apúblico namesmaépocaemqueobrascomo Raízes do Brasil e Casa Grande e Senzala começavam a exercer grande influência no meio acadêmico brasileiro.

Cada detalhe de Descobrimento do Brasil colaboracomaversãodahistóriaquelegitima o poder da eurotecnologia. Depois dos primeiros encontros dos portugueses com os ameríndios (enfatizando, é claro, o espanto destesúltimoscomatecnologiaecomovinho dos primeiros), o filme culmina com a emblemática Primeira Missa. E como modelo paraa encenação, M auro fez a escol hasegura: a célebre obra de Vitor Meirelles. $O$ filme de Mauro recompõecuidadosamente a pintura, montando um portentoso tableau, num esforço de dar "vida e movimento" à cena concebida por Meirelles. As árvores parecem estar nos mesmos lugares escolhidos por Meirelles. Inda que o frei Henrique de Meirellessejabemmaisjovemqueo deMauro, na cena geral os índios e os portugueses caminham até ocupar quase as mesmas posições que os personagens da pintura. $O$ clímax ex(s)tático, acompanhado pela grandiosamúsicacoral deVilla-Lobos, ocorre quando o padreerguea eucaristia em direção à cruz. Mauro corta o plano geral proposto por Meirelles e enquadra em detalhe o nó dramático da composição de Meirelles, mostrando frei Henriqueem primeiro plano.

No quadro de Meirelles os fundadores portugueses ocupam o centro da cena; no filme de Mauro eles têm, além disso, o status de narradores privilegiados, etodas as ações são mostradas sob seu ponto devista, ao som de sua voz e à luz de sua escrita. O ato civilizador dos portugueses, tanto no quadro como nesta cena do filme, irradia luz para a naturezaao redor e, éclaro, paraosindígenas, que aparecem infantilizados, embevecidos pelo espetáculo. Além disso, a presença contrastante - e claramente em primeiro plano - de mulheres e crianças entre os nativos acentua o caráter "paterno/ ativo/ fálico" atribuído aos portugueses. Como em outrosrelatos da colonização, os personagens queintegram a frota de Cabral são todos eles do sexo masculino, prontos a penetrar na terra que (até nosso século) foi virgem. ${ }^{7}$

Há, desse modo, um continuum intertextual de representações que parte da Carta de Caminha, sai datela deM eirellese passa pelo filme de Mauro, reafirmando a concepção figurativa do evento eproduzindo uma aura de autencidadejá intensi ficada pela longevidade e pela onipresença do ícone.

Esse discurso aparentemente unívoco (que compõe o Grande Intertexto Oficial do Descobrimento) é assim rearticulado em diferentes versões: personagens e paisagens, a partir da versão escrita de Vaz deCaminha, são (re)compostos por M eirelles, cuja técnica, além disso, produz colagens de paisagens. A colagem de Meirelles, por sua vez, é (re)traduzida pela filmagem de Mauro.

Nesse processo de representação (sempre naturalista), baseada na verossimilhança e que se quer presentação, geografias e estratégias estéticas diferentes são mobilizadas com o mesmo objetivo: num processo de transfiguração mimética, significar o ato fundador da nacionalidade. 
Entretanto, as rupturas possíveis desta corrente de significantes - produto das sucessivasmontagensecolagensdeelementos distintos - permitiriam leituras divergentes de um discurso que se pretende estável, destacandoseu caráter francamenteficcional. É orisco quesecorreemqual quer reelaboração textual. Dessa forma, aquilo que poderia ser tomado como representação figurativa (cada elo da corrente) se exporia como reinterpretação al usiva (pelo contrasteentreos elos, montados), em quea impressão de realidade eas idéias a respeito do evento preval eceriam sobreaautenticidadequea própria ideologia do naturalismo advoga. Mas, domesmo modo que a narrativa cinematográfica hegemônica valoriza a continuidade como método de se anular apresençadeelipsesespaço-temporais, o continuum discursivo do descobrimento se reveste de oficialidade, impedindo que o caráter ficcional de suas representações emerja.

\section{Parênteses: a Independência}

A sescolhas estéticas de Mauro para D escobrimento do Brasil seriam seguidas por outros autores do cinema brasileiro, preocupados em conferir esse caráter de legitimidade a seusfilmes. Em 1970, no apogeu da repressão promovida pelo regime militar, Carlos Coimbra dirigiu o divulgadíssimo Independência ou M orte, produção que reuniu alguns dos nomes mais populares da telenovela da época, comoTarcísio M eiraeGlória Menezes. Naquele momento, o governo encorajava a produção defilmes históricos, eo trabal ho de Coimbra foi muito bem incorporado ao discurso oficial do regime. $O$ filme foi por muitos anos programação obrigatória na TV nos feriados de 7 de setembro.

A concepção cênica de Independência ou $M$ orte segue as regras estabelecidas pelas convenções hollywoodianas, e a produção dispôs de muito mais recursos e condições técnicas que aquelas disponíveis para Descobrimento do Brasil em 1937. Indepen- dência ou M orte foi filmado em technicolor, teve como locação muitos edifícios do século XIX e ostenta um luxuoso figurino, o que indica um esforço em semanter o discurso da autenticidade histórica. Assim mesmo, a cenografiamesclaobjetoseedifícios detempos diferentes, como é o caso das edificações conhecidas como Paradas da M arquesa, na velha estrada do Caminho do Mar, que liga São Paulo a Santos. Idealizadas pelo arquitetoVictor Dubugras em estilo neocolonial no início doséculoXX, nofilmeasparadasservem de cenário para os encontros amorosos do imperador-Tarcísio com a marquesa-Glória, escolha que deve confundir os espectadores quanto à autenticidade - tanto do discurso arquitetônico quanto do fílmico.

Asrazõesquefizeram Pedrol parar àbeirado I piranga na tarde de 7 de setembro têm sido alvo de longuíssima controvérsia, que não interessa aqui. No entanto, a imagem que perpetua a cena em cadernos escolares, livros didáticos e selos comemorativos tem sido quase sempre a do G rito do I piranga, quadro pintado por Pedro Américo em 1888. Como Meirelles, o artista também era um dos protegidos de Pedro II, tendo sido agraciado com bolsas, estipêndios eviagens deestudos por sua alteza imperial. Seu trabalho é mais expressionista do que o de Meirelles, e sua visão do evento serevela, em cores vibrantes, no vigor desuas pinceladas. No quadro, Pedro I évisto a cavalo, empunhando sua espada no momento em que supostamente estaria gritando "Independência ou morte!", enquanto os soldados que o acompanham virilmente puxam as rédeas de seus energéticos cavalos. Os soldados, em primeiro plano, ostentam uniformes impecáveis e rodeiam aquele que seria o primeiro imperador da nova nação. Num dos cantos inferiores da moldura A mérico colocou uma testemunha da cena histórica: um camponês descalço a puxar um carro de bois. Esse personagemtemsidolido comorepresentante do povo, cuja presença legitimaria o gesto do príncipe. Em seu filme, Carlos Coimbra faz uso da mesma retórica que Mauro escolheu 
em 1937: os atores vagarosamentesecolocam nasmesmasposições emqueestão napintura, compondo a mesma cena cívica.

\section{O Intertexto Desafiante}

O cinema deGlauber podeser visto como um desafio a essa estéticanaturalista. A representação de eventos históricos em seus filmes expõe a montagem de fontes e leituras diferentes da história. Terra em Transe, por exemplo, também apresenta uma Cena do Descobrimento, mas os resultados da experimentação de Glauber estão muito distantes das narrativas complacentes dos filmes que acabo decitar, que recorrem à arte acadêmica para confirmar as versões oficiais dos eventos retratados.

Terra em Transeseestrutura por umanarração em voz off, na primeira pessoa, esugere uma montagem dos fragmentos da memória do personagem Paulo Martins (vivido na tela por Jardel Filho), um jornalista no momento de sua agonia final. Esses fragmentos são ordenados de um modo distinto da linearidadecausal dasnarrativasconvencionais, que indicaria o estado emocionalmente confuso - ou mesmo onírico - do personagem no momento desua própria morte. Desse ponto devista, a não-linearidade das cenas deTerra em Transe sugere a propriedade de uma leitura psicanalítica (com o foco voltado para asubjetividadedo personagem-narrador) que poderia se sobrepor a outras possibilidades de leitura. Estas outras possibilidades, no entanto, podem operar de acordo com diferentes representações de tempo em diferentes contextos culturais - representações que não seriam necessariamente explicadas pela conformidade ao mundo aparentemente entrópico do inconsciente freudiano. N uma perspectivaetnográfica, por exemplo, estas possibilidades podem variar enormemente, de acordo com várias visões de mundo. Mas fiquemos, por aqui, com a memória de Paulo Martins como a chave da organização narrativa de Terra em Transe.
O Descobrimento (re)construído em Terra em Transeestáclaramenteligadoàhistóriaoficial do Brasil. A cena é descrita por Ismail Xavier como a do "mito dafundação" queestabelece a conexão da saga do personagem Martins com o destino histórico de seu país. ${ }^{8}$ Neste momento do filme, o personagem central éo mentor da juventude de Paulo Martins: o político conservador Porfírio Diaz (Paulo Autran)..$^{9} \mathrm{O}$ tom da cena é o de um ritual solene, de movimentos lentos, sublinhados por batuques afrobrasileiros e pela música erudita de Villa-Lobos. Diaz é mostrado na vastidão deuma praiadeserta, vestindo terno egravata, carregando uma bandeira negra, e acompanhado por três figuras: um monge, um navegador do século XVI e um indígena. Osquatro personagensseaproximam deuma enorme cruz de madeira, fincada na areia; Diaz bebe de um cálice barrocamente decorado. Parece evidente que a cena é a reelaboração do Descobrimento do Novo Mundo pelos europeus (a chegada à praia) e da Primeira Missa (que aqui nesse caso é celebrada por Diaz, e não pelo padre). Mas uma cena tão alegorizada não permite ser contida por apenas uma leitura.

N umaperspectivarealista, asoleneseriedade da atuação, a trilha sonora e o deslocamento temporal indicado nas roupas (que mesclam os séculos XVI eXX) trazem absurdo eironia à cena histórica, mesmo quando se leva em conta o estado agônico do personagemnarrador. De certo modo, a cena evoca o discurso delegitimação da classedominante, pois o personagem Diaz representaria a geração contemporânea de dominadores, herdeira dos primeiros colonizadores. $\mathrm{E}$ ao mesmo tempo em que reafirma a herança colonial e os valores europeus (emblematizados aqui pelo cristianismo), ela inclui a respeitosa adesão indígena. Masseo papel de Diaz na "missa" parece ser um fator suficientemente complicador (num gesto napoleônico, o chefesecular assumeo serviço do padre), os retratos (nada naturalistas) que Terra em Transe faz do colonizador edo índio aprofundam ainda mais a complexidade. 
Como nota Ismail Xavier, as roupas desses personagenslembramfantasias decarnaval, ${ }^{10}$ que contrastam com o traje do engravatado Diaz. O índio está carnavalesca e completamente vestido - não nu, como Caminha relataenemcomo sexodiscretamenteornado, como Meirelles retrata . O colonizador, por sua vez, érepresentado por uma celebridade indubitavelmente carnavalesca: Clóvis Bornay, o campeão dos concursos defantasia no carnaval do Rio de Janeiro. Bornay é um especialista em história, que já declarou repetidas vezes que suas fantasias são alegorias cuidadosamente pesquisadas em documentoshistóricos. Osbordadosdaroupa do conquistador eo manto de penas do índio se constituem, desse modo, em alegorias dentro da al egoria, numa estratégia narrativa que opera um imediato efeito de distanciamento e apresenta os eventos do Descobrimento eda PrimeiraM issa como discursos, em óbvia recusa do naturalismo, apontando possibilidades para o desdobrar de significados múltiplos. A Terra em Transe de Glauber questionaaCarta deCaminha, rejeita aM issa de Meirelleseabreumoutro modo de fazer cinema e história, desviando radicalmente o percurso do continuum textual a que mereferi.

Esta reinterpretação alegórica/ histórica de Terra em Transe está também distante da revisão promovidapor autores progressistas, quetêm seaplicado na reescritura da história do Brasil não mais como o ponto de vista das autoridades coloniais ou a presente classe dominante, mas como o resultado da dominação econômica e das lutas políticas. Daí a mudança de tom narrativo, no sentido de fazer ouvir vozes relegadas à subalternidade. Mas são poucos os trabal hos quetêm proposto alternativas para os formatos convencionais e lineares das narrativas cronológicas da academia. O cinema de Glauber, além denão seguir as exigências das narrativas lineares e das estratégias naturalistas, enredaesincretiza tempos elugares de modo a (re)situar os eventos históricos, sem pleitear qualquer autenticidade. Desse modo, as escol has estéticas de Glauber aprofundam o diálogo do Cinema Novo com as práticas e formasculturaispopulares - como asformas carnavalescas, por exemplo -, apontando para possibilidades textuais ainda pouco exploradas pelas várias áreas de expressão cultural no Brasil .

\section{Notas}

1 Há diversas ediçées da Carta. Escolhi datar a Carta a El Rey D. Manud, org. Leonardo Arroyo (Säo Paulo: Dominus, 1963), p. 6.

2 Op. at, p. 4 .

3 Idem, p. 64.

4 Idem.

5 O Sul da Behia é a única região da América do Sul que possui a mesma flora da regiz̃o amazônica, apesar deselocalizar a milhares de quilômeros de distânáa daquela região.

60 excelente Cinema e História do Brasil, de Aládes Frére Ramos \& Jeen-ClaudeBemardet (Säo Paulo: Contexto, 1988), disauteessa quetãõo da representação realista da história; já Sérgio Augusto, em artigo na Folha de S. Paulo, alega que a escassez de filmes "históicios" brasilerios sedeveàfalta detenologia adequada para esse tipo de filme no Brasil - como se 0 abastado padrão hollywoodiano significasse a única possibilidade de representação histórica no cinema. Ver "Cinema americano nunca se interessou por Colombo", 11 de outubro de 1992.

7 Para uma análise dessas meáforas, ver o atigo de Ella Shohat, "Imaging Terra Incognita: The Disciplinary Gaze of the Empire", in Public Culture, vol 3, no 2, Spring 1991

\section{Alegorias do Subdesenvolvimento (São Paulo: Brasiliense, 1992)}

9 Diaz é homônimo do ditador mexicano do séaulo XIX, mas não pareceter muita reação com de 0 personagem representado por Autran é típico do século XX, sendo representante do capital multinacional numa republiqueta latino-americana.

10 Op. at 